\title{
Plantamajoside exerts antifibrosis effects in the liver by inhibiting hepatic stellate cell activation
}

\author{
YUN WANG $^{1}$ and DONGLIANG YAN ${ }^{2}$ \\ ${ }^{1}$ Department of Pharmacy, Obstetrics and Gynecology Hospital Affiliated to Nanjing Medical University, \\ Nanjing, Jiangsu 210004; ${ }^{2}$ Department of General Surgery, The Second Affiliated Hospital of \\ Nantong University, Nantong, Jiangsu 226001, P.R. China
}

Received August 4, 2018; Accepted March 18, 2019

DOI: $10.3892 / \mathrm{etm} .2019 .7843$

\begin{abstract}
The pathogenesis of liver fibrosis involves the activation of hepatic stellate cells (HSCs) into muscle fiber cells and fibroblasts. The aim of the current study was to investigate whether plantamajoside (PMS) exerted antifibrosis effects by affecting HSCs activation and survival during liver fibrosis, and to investigate the underlying mechanism. HSC-T6 cells were activated by exposure to platelet-derived growth factor BB (PDGF-BB), and were subsequently treated with increasing concentrations of PMS $(0,20,40,80$ and $160 \mu \mathrm{g} / \mathrm{ml}$ ). Cell viability, apoptosis, migration and invasion were determined using the Cell Counting Kit-8 (CCK-8) assay, flow cytometry and the Transwell assay, respectively. Results indicated that PDGF-BB significantly activated HSC-T6 cells, demonstrated by increased cell proliferation, enhanced cell migration and invasion as well as increased expression of $\alpha$-smooth muscle actin ( $\alpha$-SMA) and collagen type $1 \alpha 1$ (Col1 $\alpha 1)$. PMS inhibited proliferation, induced cell apoptosis and prevented cell migration and invasion in PDGF-BB-treated HSC-T6 cells in what appeared to be a dose-dependent manner. PMS appeared to dose-dependently reduce the protein and mRNA levels of $\alpha$-SMA and Coll $\alpha 1$ in PDGF-BB-treated HSC-T6 cells. Furthermore, the results of the present study suggested that PMS administration inhibited the protein expression of phosphorylated-protein kinase B in what appeared to be a dose-dependent manner. In conclusion, the data indicated that PMS exhibited an antifibrotic effect in the liver by inhibiting hepatic stellate cell activation and survival.
\end{abstract}

Correspondence to: Dr Dongliang Yan, Department of General Surgery, The Second Affiliated Hospital of Nantong University, 6 North Huaixiang Road, Nantong, Jiangsu 226001, P.R. China E-mail: yand10804@163.com

Key words: liver fibrosis, hepatic stellate cells, plantamajoside, platelet-derived growth factor

\section{Introduction}

Liver fibrosis is a compensatory response in the process of tissue repair following liver damage and inflammation caused by various chronic pathogenic factors (including viral infection, immune attack and drug toxicity) $(1,2)$. If liver fibrosis is diagnosed and treated at an early stage, normal liver tissue structure and function may be restored. However, if left untreated it progresses to irreversible end-stage cirrhosis and liver cancer and has an extremely high mortality (3). The pathogenesis of liver fibrosis is complex. Although different etiological factors involve diverse pathophysiological processes, the activation of hepatic stellated cells (HSCs) is a common process in the development of liver fibrosis (4). A variety of immune factors activate HSCs and increase the expression levels of $\alpha$-smooth muscle actin ( $\alpha$-SMA) and collagen type $1 \alpha 1$ (Col1 $\alpha 1)$, thereby forming collagen fibers and extracellular matrices that lead to liver fibrosis (5). At present, various drugs have been used for the treatment of liver fibrosis, including vitamins, nucleoside analogs, liver-protecting enzymes and interferon treatment $(6,7)$. However, their efficacy remains unsatisfactory, and the prevention and treatment of liver fibrosis are challenging $(7,8)$. Therefore, it is of great practical significance to elucidate the mechanisms underlying the occurrence and development of liver fibrosis and to identify effective strategies for its treatment.

Plantamajoside (PMS), a natural compound extracted from Psyllium asiatica, has long been used in folk medicine (9). PMS is a phenylpropanoid glycoside and previous studies have revealed that it has a wide range of biological activities, including antioxidant, anti-inflammatory and antitumor effects (10-13). A recent study demonstrated that PMS suppresses the progression of respiratory inflammatory diseases by inhibiting the inflammatory response (14). Furthermore, PMS regulates human umbilical vein endothelial cell adhesion function via the mitogen-activated protein kinase/nuclear factor- $\kappa b$ signaling pathway (15). However, the potential effects of PMS on liver fibrosis have not been investigated.

The activation and proliferation of HSCs as well as their synthesis and secretion of extracellular matrix serve important roles in the development of liver fibrosis (16). Activated HSCs may transform into myofibroblasts, secreting a large amount of 
collagen fibers to promote the formation of liver fibrosis $(5,17)$. Inhibiting the activity of HSCs may therefore effectively delay the progression of liver fibrosis $(5,18)$. Activated HSCs have been widely used as a cell model of liver fibrosis (19-21). Platelet-derived growth factor BB (PDGF-BB)-induced HSC-T6 cell activation has been previously used to study liver fibrosis in vitro $(20,22)$.

The present study aimed to investigate whether PMS may prevent liver fibrosis by affecting the activation and survival of HSCs, and to explore the underlying molecular mechanism. The results obtained in the current study may provide a theoretical basis for the development of novel treatment strategies for the clinical treatment of liver fibrosis.

\section{Materials and methods}

Cell culture and treatment. HSC-T6 cells (cat no. R-HSC-T6; Shanghai Kalang Biological Technology Co., Ltd., Shanghai, China) were cultured in Dulbecco's modified Eagle medium (DMEM; Invitrogen; Thermo Fisher Scientific, Inc., Waltham, MA,USA) containing $10 \%$ fetal bovine serum(FBS; Invitrogen; Thermo Fisher Scientific, Inc.) and 1\% penicillin/streptomycin (Gibco; Invitrogen; Thermo Fisher Scientific, Inc.). The cells were incubated at $37^{\circ} \mathrm{C}$ with $5 \% \mathrm{CO}_{2}$.

To activate HSC-T6 cells, cells were serum-starved in FBS-free DMEM for $24 \mathrm{~h}$ and then exposed to $10 \mathrm{ng} / \mathrm{ml}$ PDGF-BB (Sigma-Aldrich; Merck KGaA,Darmstadt, Germany) as previously described $(19,20)$.

HSC-T6 cells were subsequently treated with increasing concentrations $(20,40,80$ and $160 \mu \mathrm{g} / \mathrm{ml})$ of PMS (purity $>99 \%$; Best-Reagent Company, Chengdu, China), or equal amount of solvent control, at $37^{\circ} \mathrm{C}$ for the time indicated in the different experiments. PMS was dissolved in a solution of equal ratio ethanol and ultrapure water.

Cell proliferation assay. The Cell Counting Kit-8 (CCK-8) assay was performed to determine the effect of PMS on the proliferation of HSC-T6 cells. First, $1 \times 10^{4}$ HSC-T6 cells without PDGF-BB treatment were plated per well in a 96-well plate and treated with increasing concentrations $(0,20,40,80$ and $160 \mu \mathrm{g} / \mathrm{ml}$ ) of PMS for $48 \mathrm{~h}$. In addition, PDGF-BB treated HSC-T6 cells ( $1 \times 10^{4}$ cells per well) were plated into a 96-well plate and treated with increasing concentrations $(0,20,40,80$, and $160 \mu \mathrm{g} / \mathrm{ml}$ ) of PMS for $48 \mathrm{~h}$, or treated with $160 \mu \mathrm{g} / \mathrm{ml}$ PMS for 12,24 and $48 \mathrm{~h}$. A total of $10 \mu \mathrm{l}$ CCK-8 solution was added to each well and incubated at $37^{\circ} \mathrm{C}$ for an additional $2 \mathrm{~h}$. Cell proliferation was assessed by measuring the absorbance at a wavelength of $450 \mathrm{~nm}$ using a FLUOstar ${ }^{\circledR}$ Omega microplate reader (BMG Labtech $\mathrm{GmbH}$, Ortenberg, Germany).

Cell invasion and migration assay. The effect of PMS on the migration and invasion of PDGF-activated HSC-T6 cells was determined using Transwell assay. In brief, chamber inserts (24-well transwell plate; $8 \mathrm{~mm}$ pore size) were coated with $200 \mathrm{mg} / \mathrm{ml} \mathrm{Matrigel}{ }^{\boxplus}$ at $37^{\circ} \mathrm{C}$ and dried overnight under sterile conditions for the invasion assay. A total of $1 \times 10^{4}$ cells HSC-T6 cells were suspended in serum-free DMEM containing various concentrations of PMS $(0,20,40,80$ and $160 \mu \mathrm{g} / \mathrm{ml})$ and seeded into the upper chamber. A total of $600 \mu \mathrm{l}$ DMEM containing 20\% FBS was added to the lower chamber. Cells were incubated for $48 \mathrm{~h}$ at $37^{\circ} \mathrm{C}$. Migratory or invasive cells on the basolateral side of the insert were fixed with $100 \%$ methanol at room temperature for $10 \mathrm{~min}$ and stained with $0.1 \%$ crystal violet at room temperature for $15 \mathrm{~min}$. The migratory or invasive cells in five random fields were counted using a light microscope (magnification, x200).

Cell apoptosis assay. Cell apoptosis in the present study was analyzed using the Annexin V-Fluorescein Isothiocyanate (FITC)/Propidium Iodide (PI) Apoptosis Detection kit (cat no. 70-AP101-100; MultiSciences, Hangzhou, China) following the manufacturer's protocol. After treating with various concentrations $(0,20,40,80$, and $160 \mu \mathrm{g} / \mathrm{ml})$ of PMS for $48 \mathrm{~h}$, PDGF-activated HSC-T6 cells were stained with $5 \mu \mathrm{l}$ Annexin V-FITC and $5 \mu \mathrm{l}$ PI for $30 \mathrm{~min}$ at room temperature in the dark. A flow cytometer was used to analyze cell apoptosis. The early and late apoptosis rates were calculated in the current study using WinMDI software (version 2.5; http://www.cyto.purdue.edu/flowcyt/software/Winmdi.htm).

Reverse transcription-quantitative polymerase chain reaction $(R T-q P C R)$. Total RNA was extracted from HSC-T6 cells using TRIzol $^{\circledR}$ reagent (Invitrogen; Thermo Fisher Scienfitic, Inc.), according to the manufacturer's protocol, and reverse-transcribed into cDNA using the miScript Reverse Transcription kit (Qiagen $\mathrm{GmbH}$ ) according to the manufacturer's protocol. qPCR was subsequently performed using the SYBR ${ }^{\circledR}$ Green PCR Master mix (Thermo Fisher Scientific, Inc.). The sequences of the primer pairs used are presented in Table I. Amplification conditions for qPCR were as follows: $5 \mathrm{~min}$ at $95^{\circ} \mathrm{C}$, followed by 35 cycles at $95^{\circ} \mathrm{C}$ for $15 \mathrm{sec}, 40 \mathrm{sec}$ at $55^{\circ} \mathrm{C}$, and $72^{\circ} \mathrm{C}$ for $1 \mathrm{~min}$. mRNA levels were quantified using the $2^{-\triangle \Delta C q}$ method and normalized to the internal reference gene GAPDH (23).

Western blot assay. Total protein was extracted from HSC-T6 cells treated with or without PDGF-BB, or from PDGF-activated HSC-T6 cells treated with various concentrations $(0,20,40,80$ and $160 \mu \mathrm{g} / \mathrm{ml})$ of PMS for $48 \mathrm{~h}$, using radioimmunoprecipitation buffer (cat no. P0013E; Beyotime Institute of Biotechnology, Shanghai, China). Total protein was quantified using a bicinchoninic acid assay kit (Pierce; Thermo Fisher Scientific, Inc.). Protein samples (30 $\mu \mathrm{g} / \mathrm{lane})$ were separated via SDS-PAGE on a $12 \%$ gel. The separated proteins were subsequently transferred onto a polyvinylidene difluoride membrane and blocked in 5\% skimmed milk at room temperature for $1.5 \mathrm{~h}$. The membranes were incubated with the following primary antibodies: Anti-p-AKT (cat no. 4060), anti-AKT (cat no. 4685), anti-BCL-2 (cat no. 4223), anti-Bax (cat no. 5023) anti- $\alpha$-SMA (cat no. 19245), anti-Col1 $\alpha 1$ (cat no. 84336) and $\beta$-actin (cat no. 4970; all 1:1,000; Cell Signaling Technology Inc., Danvers, MA, USA) overnight at $4^{\circ} \mathrm{C}$. Membranes were subsequently incubated with a horseradish peroxidase-conjugated secondary antibody (cat no. 7074; 1:2,000; Cell Signaling Technology Inc.) at room temperature for $2 \mathrm{~h}$. Protein bands were visualized using the Enhanced Chemiluminescence Detection system (Thermo Fisher Scientific, Inc.) according to the manufacturer's protocol. The band densities of p-AKT were analyzed using Gel-Pro-Analyzer software (version 6.3; Media Cybernetics, 
Table I. Primer sequences used for reverse transcription-quantitative polymerase chain reaction.

Sequence $\left(5^{\prime}-3^{\prime}\right)$

\begin{tabular}{lll}
\cline { 2 - 3 } Primer & \multicolumn{1}{c}{ Forward } & \multicolumn{1}{c}{ Reverse } \\
\hline BCL2 & TTGGATCAGGGAGTTGGAAG & TGTCCCTACCAACCAGAAGG \\
BAX & CGTCCACCAAGAAGCTGAGCG & CGTCCACCAAGAAGCTGAGCG \\
$\alpha$-SMA & TCCAGAGTCCAGCACAATACCAG & AATGACCCAGATTATGTTTGAGACC \\
Col1 $\alpha 1$ & GTGAGACAGGCGAACAGG & GACCAGCAGGACCAGAGG \\
GAPDH & CTTTGGTATCGTGGAAGGACTC & GTAGAGGCAGGGATGATGTTCT
\end{tabular}

Coll $\alpha 1$, collagen type $1 \alpha 1 ; \alpha$-SMA, $\alpha$-smooth muscle actin.
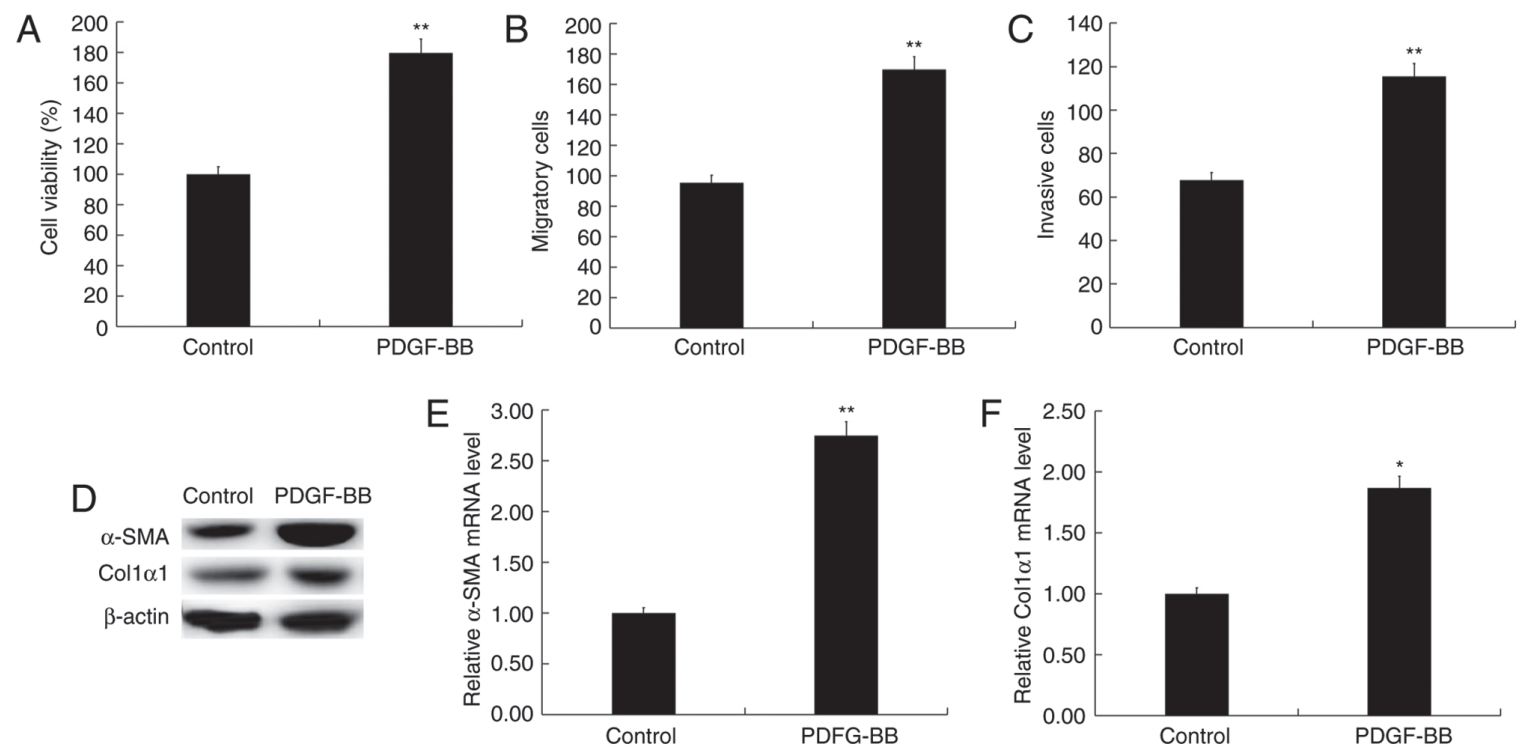

Figure 1. Effect of PDGF-BB on HSC-T6 cells. HSC-T6 cells were treated with $10 \mathrm{ng} / \mathrm{ml}$ PDGF-BB for $24 \mathrm{~h}$. (A) Cell viability was detected using the Cell Counting Kit-8 assay and expressed as \% of the control. The cell (B) migration and (C) invasion were measured using a Transwell assay. (D) The protein levels of $\alpha$-SMA and Coll $\alpha 1$ were detected using western blotting. The mRNA levels of (E) $\alpha$-SMA and (F) Coll $\alpha 1$ were determined using reverse transcription-quantitative polymerase chain reaction. Data are presented as the mean \pm standard deviation. ${ }^{*} \mathrm{P}<0.05,{ }^{* * *} \mathrm{P}<0.01$ vs. the control group (HSC-T6 cells not treated with PDGF-BB). PDGF-BB, platelet derived growth factor. PDGF-BB, platelet-derived growth fact or BB; $\alpha$-SMA, $\alpha$-smooth muscle actin; Colla1, collagen type $1 \propto 1$.

Inc., Rockville, MD, USA), and the relative protein level of p-AKT was shown as fold of the control group. Each experiment was performed three times.

Statistical analysis. Results were expressed as the mean values \pm standard deviation. All data analyses were performed using SPSS software (version 17; IBM Corp., Armonk, NY, USA). Comparisons between two groups were made using Student's t-test and comparisons between multiple groups were analyzed by one-way analysis of variance with a Tukey's post-hoc test. All experiments were repeated three times. $\mathrm{P}<0.05$ indicated a statistically significant difference.

\section{Results}

PDGF-BB activates HSC-T6 cells. HSC-T6 cells were activated by treatment with $10 \mathrm{ng} / \mathrm{ml}$ PDGF-BB as previously described $(19,20)$. PDGF-BB significantly increased HSC-T6 cell proliferation (Fig. 1A), migration (Fig. 1B) and invasion (Fig. 1C). Furthermore, compared with HSC-T6 cells which were not treated with PDGF-BB, $\alpha$-SMA and Coll $\alpha 1$, markers of activated HSCs, were significantly increased in PDGF-BB-treated HSC-T6 cells (Fig. 1D-F). Taken together, the data indicated that HSC-T6 cells were activated by treatment with PDGF-BB.

PMS inhibits activated HSC-T6 cell proliferation. HSC-T6 cells were treated with various concentrations $(0,20,40,80$ and $160 \mu \mathrm{g} / \mathrm{ml}$ ) of PMS for $48 \mathrm{~h}$. Cell viability was subsequently measured. Results indicated that none of the concentrations of PMS used had significant effects on the cell viability of HSC-T6 cells (Fig. 2A). Activated HSC-T6 cells were treated with various concentrations $(0,20,40,80$, and $160 \mu \mathrm{g} / \mathrm{ml})$ of PMS for $48 \mathrm{~h}$, or treated with $160 \mu \mathrm{g} / \mathrm{ml}$ PMS for 12, 24 and 48 h. CCK-8 assay results revealed that PMS inhibited HSC-T6 cell proliferation ability in what appeared to be a dose- and time-dependent manner (Fig. 2B and C). 
A

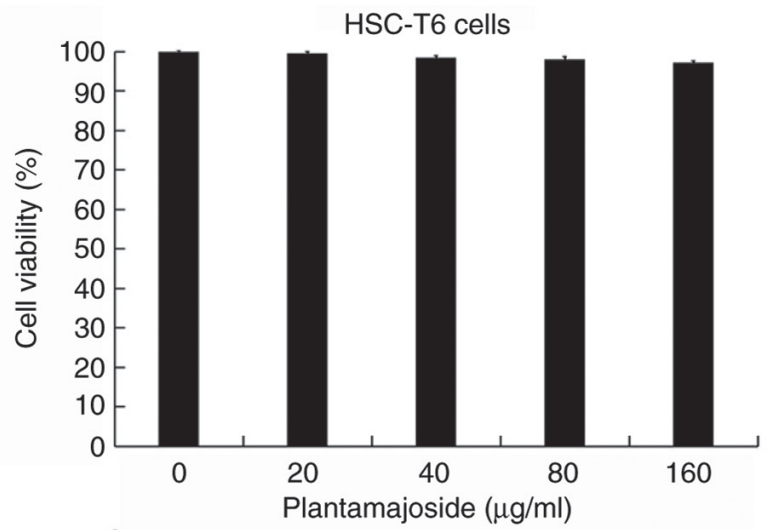

B

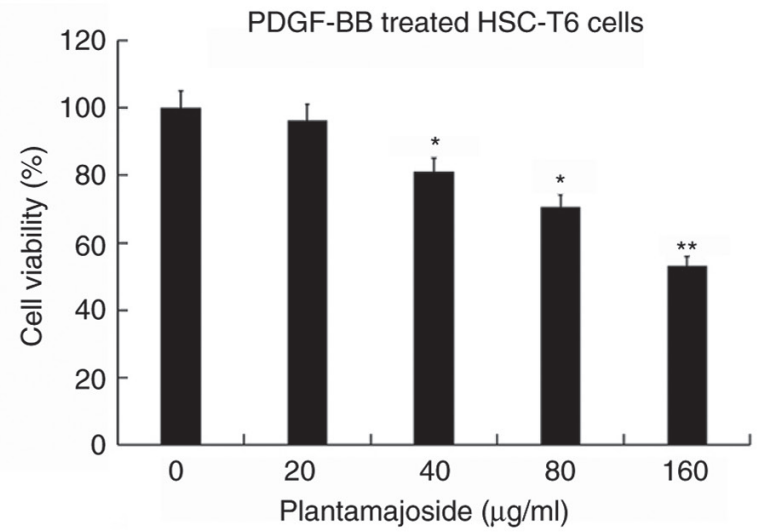

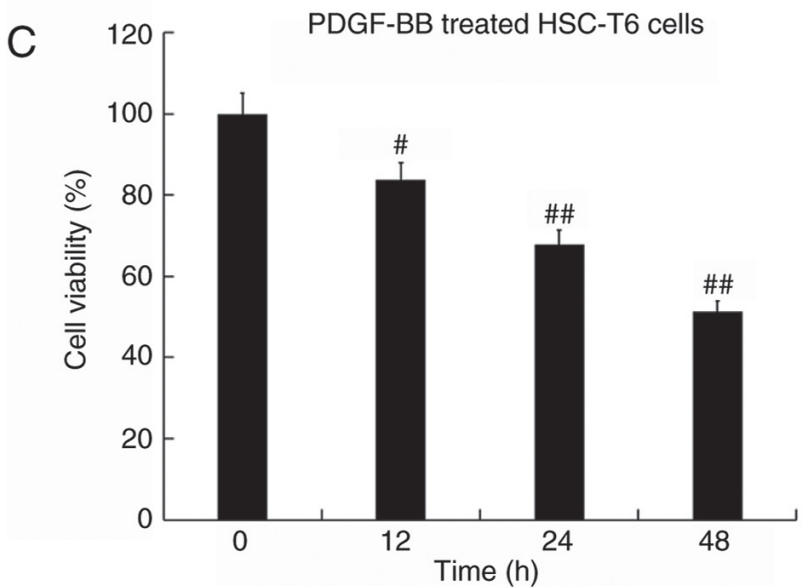

Figure 2. Effect of PMS on the cell viability of PDGF-BB treated HSC-T6 cells as determined by the Cell Counting Kit-8 assay. (A) HSC-T6 cells were treated with various concentrations (0, 20, 40,80 and $160 \mu \mathrm{g} / \mathrm{ml}$ ) of PMS for $48 \mathrm{~h}$. Activated HSC-T6 cells were treated with (B) 0,20, 40, $80 \mathrm{and} 160 \mu \mathrm{g} / \mathrm{ml}$ of PMS for $48 \mathrm{~h}$ or $(\mathrm{C}) 160 \mu \mathrm{g} / \mathrm{ml} \mathrm{PMS}$ for 12, 24 and $48 \mathrm{~h}$. Data are presented as the mean \pm standard deviation. ${ }^{*} \mathrm{P}<0.05,{ }^{* *} \mathrm{P}<0.01 \mathrm{vs}$. the $0 \mu \mathrm{g} / \mathrm{ml} \mathrm{PMS}$ treated group; ${ }^{\#} \mathrm{P}<0.05,{ }^{\# \#} \mathrm{P}<0.01$ vs. $0 \mathrm{~h}$ treatment group. PMS, plantamajoside; PDGF-BB, platelet-derived growth factor BB; $\alpha$-SMA, $\alpha$-smooth muscle actin; Col1 $\alpha 1$, collagen type $1 \propto 1$.

PMS induces apoptosis in activated HSC-T6 cells. PDGF-activated HSC-T6 cells were treated with various concentrations $(0,20,40,80$, and $160 \mu \mathrm{g} / \mathrm{ml})$ of PMS for $48 \mathrm{~h}$, then cell apoptosis was evaluated using the Annexin V-FITC/PI apoptosis detection kit. PMS induced HSC-T6 cell apoptosis in what appeared to be a dose-dependent manner (Fig. 3A and B). The protein and mRNA levels of the apoptosis-associated genes BCL-2 and BAX were measured. The results obtained suggested that the protein and mRNA levels of BCL-2 and BAX were significantly decreased and increased, respectively, in activated HSC-T6 cells, in what appeared to be a dose-dependent manner, following PMS treatment (Fig. 3C-E).

PMS inhibits activated HSC-T6 cell migration and invasion. The effect of PMS on HSC-T6 cell migration and invasion was investigated using a Transwell assay. As presented in Fig. 4A and B, compared with the control group, PMS treatment appeared to dose-dependently reduce the migratory and invasive abilities of activated HSC-T6 cells. This suggested that PMS had an inhibitory effect on the migration and invasion of activated HSC-T6 cells.

PMS inhibits $\alpha$-SMA and Coll $\alpha 1$ expression in activated HSCT6 cells. As presented in Fig. 5, the protein (Fig. 5A) and
mRNA (Fig. 5B and C) levels of $\alpha$-SMA and Col1 $\alpha 1$ were increased in PDGF-BB-treated HSC-T6 cells compared with the cells from the control group. PMS treatment appeared to dose-dependently reduce the protein and mRNA levels of $\alpha$-SMA and Coll $\alpha 1$ in PDGF-BB-treated HS-T6 cells.

PMS inhibits the activation of the PI3K/AKT signaling pathway in activated HSC-T6 cells. As presented in Fig. 6, compared with HSC-T6 cells which were not exposed to PDGF-BB, PDGF-BB treatment significantly enhanced the protein level of p-AKT in HSC-T6 cells (Fig. 6A-C). Compared with the control group, the protein level of $\mathrm{p}-\mathrm{AKT}$ was reduced in what appeared to be a dose-dependent manner in PDGF-BB-treated HSC-T6 cells following exposure to PMS (Fig. 6D-F).

\section{Discussion}

The present study demonstrated that PMS might dose-dependently inhibit the activationand proliferation in PDGF-BB-treated HSC-T6 cells. Additionally, it increased apoptosis and reduced cell migration and invasion. Furthermore, PMS inhibited the protein expression of $\mathrm{p}-\mathrm{AKT}$ in what appeared to be a dose-dependent manner in PDGF-BB-treated HSC-T6 cells. The results obtained demonstrated that PMS inhibited HSC 
A

Plantamajoside $(\mu \mathrm{g} / \mathrm{ml})$

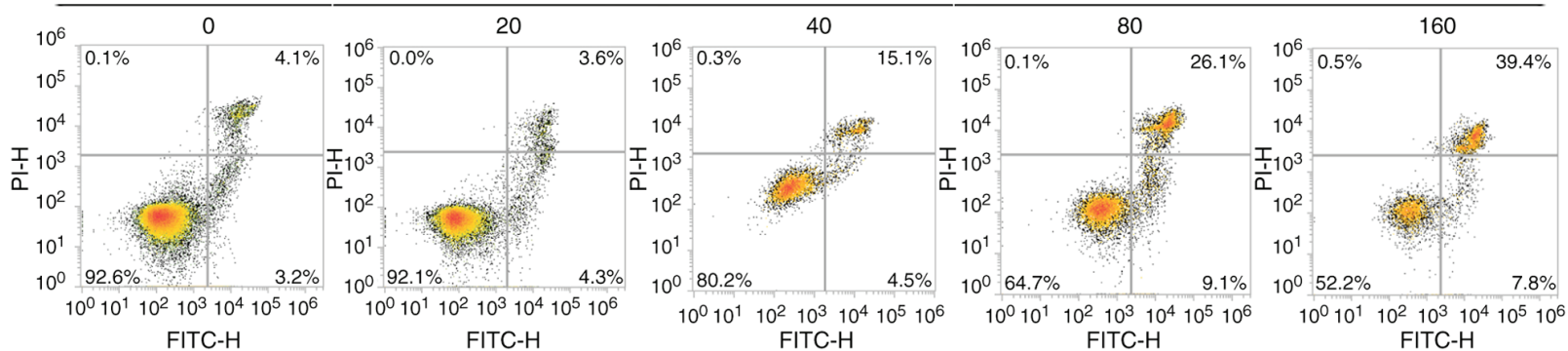

B 60

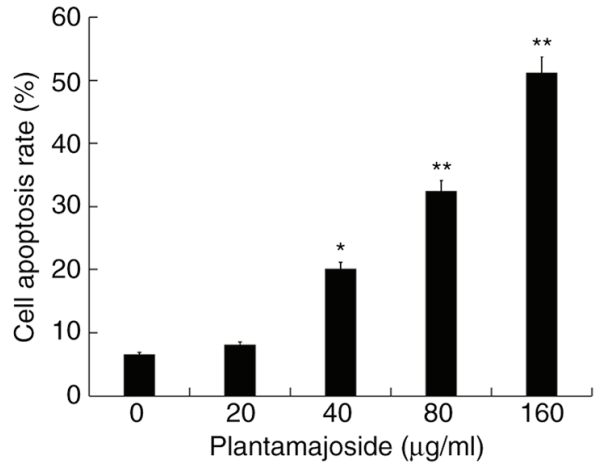

C Plantamajoside $(\mu \mathrm{g} / \mathrm{ml})$
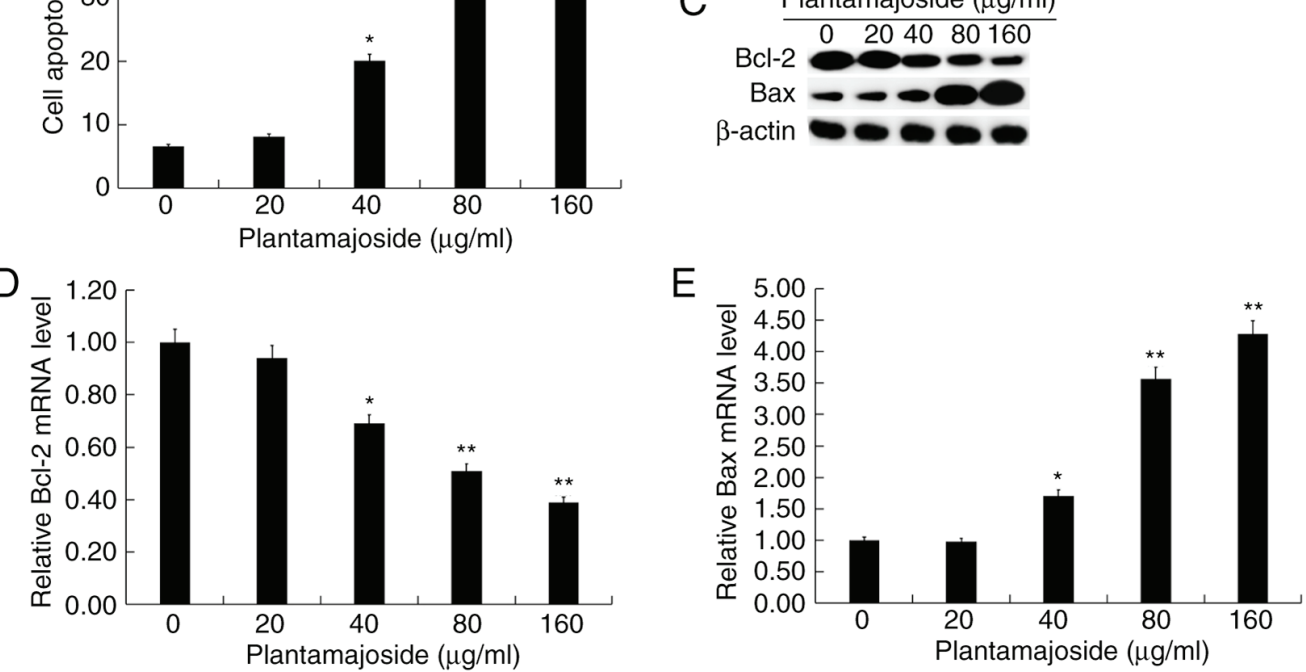

Figure 3. PMS induces apoptosis in platelet-derived growth factor BB treated HSC-T6 cells. Activated HSC-T6 cells were treated with 0, 20, 40, 80 and $160 \mu \mathrm{g} / \mathrm{ml}$ of PMS for $48 \mathrm{~h}$. (A) Representative plots and (B) quantification from flow cytometry analysis of apoptosis. The early and late apoptotic cells were calculated and expressed as \% of total cells. (C) The protein levels of BCL2 and BAX were detected using western blotting. The mRNA levels of (D) BCL2 and (E) BAX were determined using the reverse transcription-quantitative polymerase chain reaction. Data are expressed as the mean \pm standard deviation. ${ }^{*} \mathrm{P}<0.05,{ }^{* *} \mathrm{P}<0.01$ vs. control group. PMS, plantamajoside; BCL2, BCL2 apoptosis regulator; BAX, BCL2 associated X, apoptosis regulator; PI, propidium iodide; FITC, fluorescein isothiocyanate.
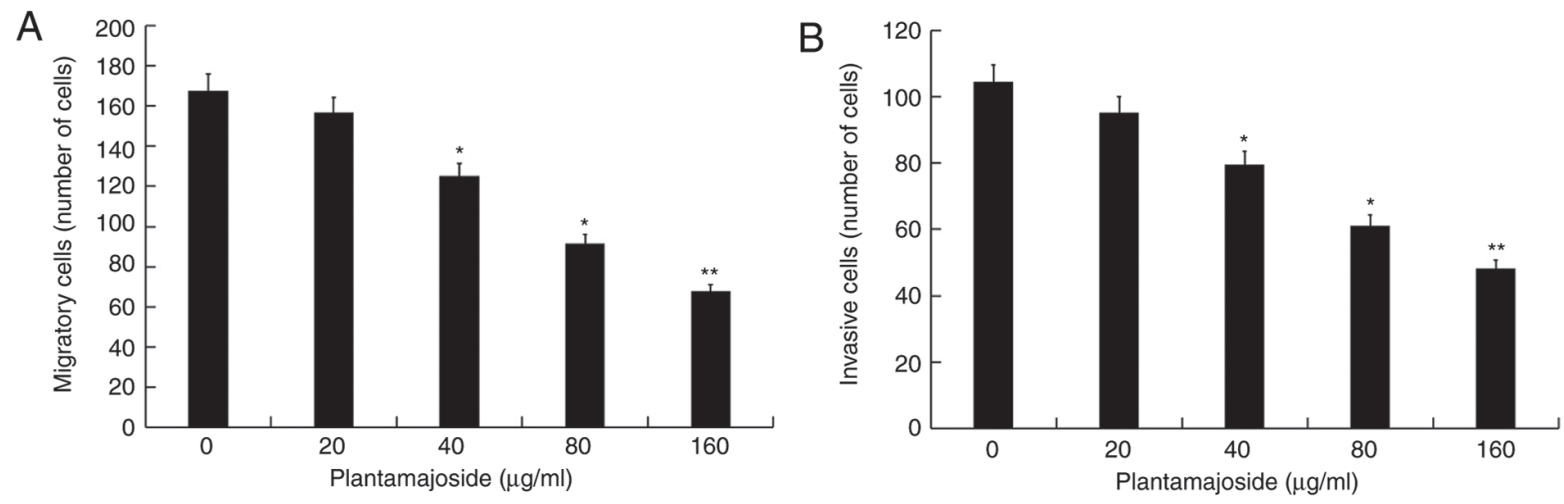

Figure 4. PMS inhibits cell migration and invasion in platelet-derived growth factor BB-treated HSC-T6 cells. Activated HSC-T6 cells were treated with 0, 20 , 40,80 and $160 \mu \mathrm{g} / \mathrm{ml}$ of PMS for $48 \mathrm{~h}$ and the number of (A) migrated and (B) invasive cells was measured using a Transwell assay. Data are presented as the mean \pm standard deviation. ${ }^{*} \mathrm{P}<0.05,{ }^{* *} \mathrm{P}<0.01$ vs. control group. PMS, plantamajoside.

activation and survival, suggesting that PMS may exhibit an antifibrotic effect in the liver.

Liver fibrosis is a healing response to various insults $(24,25)$. Advanced liver fibrosis results in a number of pathological and biochemical changes, including distortions in the normal structure of the liver, which lead to metabolic abnormalities or hepatocellular carcinoma $(26,27)$. Liver fibrosis is associated with significant morbidity (28). However, there are currently 

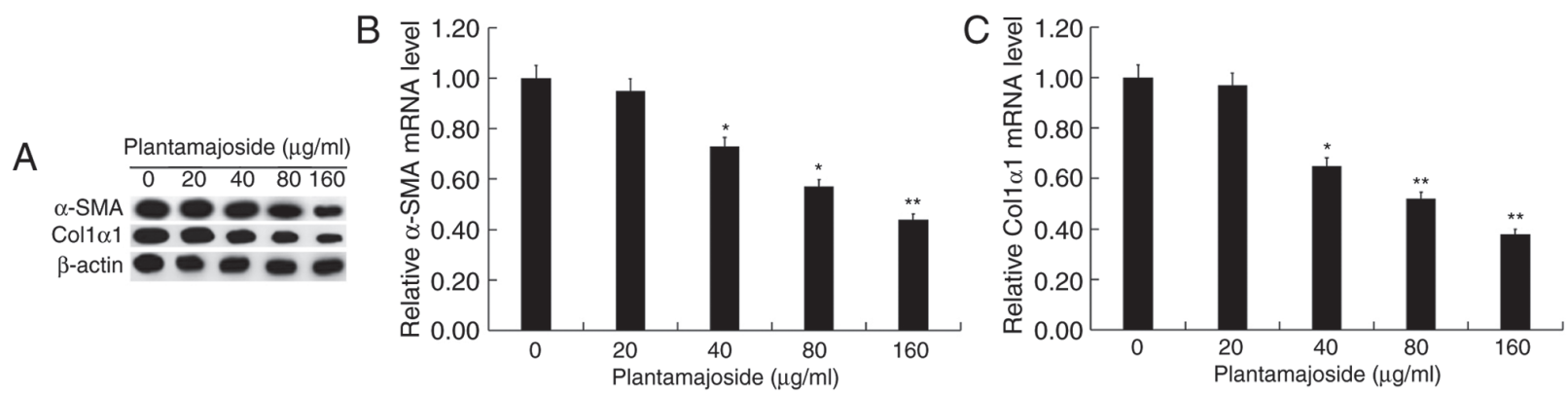

Figure 5. PMS reduces $\alpha$-SMA and Coll $\alpha 1$ expression in platelet-derived growth factor BB treated HSC-T6 cells. Activated HSC-T6 cells were treated with 0, 20,40, 80 and $160 \mu \mathrm{g} / \mathrm{ml}$ of PMS for $48 \mathrm{~h}$. (A) The protein levels of $\alpha$-SMA and Coll $\alpha 1$ were detected using western blotting. The mRNA levels of (B) $\alpha$-SMA and $(\mathrm{C})$ Col1 $\alpha 1$ were determined using the reverse transcription-quantitative polymerase chain reaction. Data are presented as the mean \pm standard deviation. ${ }^{*} \mathrm{P}<0.05,{ }^{* *} \mathrm{P}<0.01$ vs. control group. PMS, plantamajoside; $\alpha$-SMA, $\alpha$-smooth muscle actin; Coll $\alpha 1$, collagen type $1 \alpha 1$.
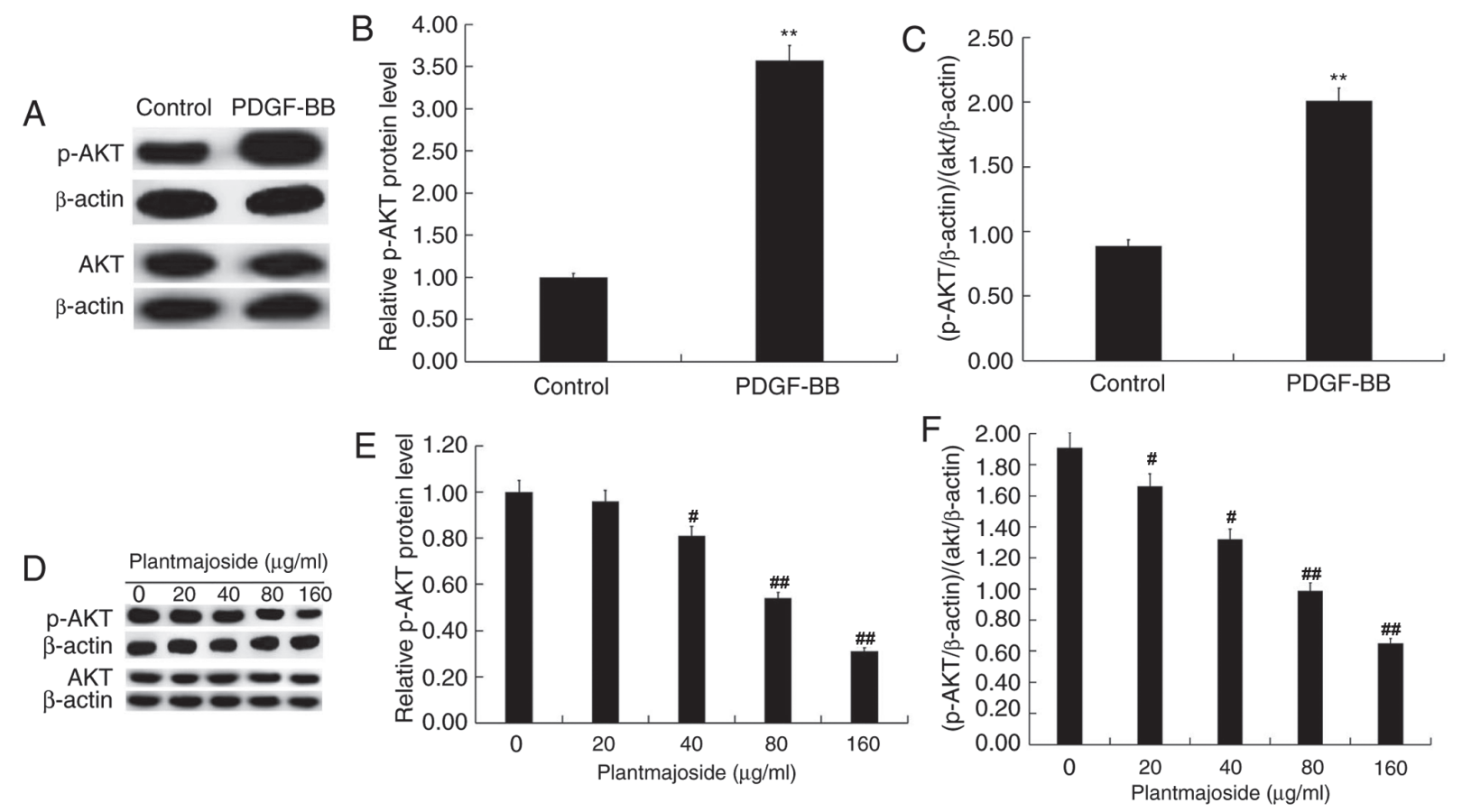

Figure 6. Effect of PMS on the phosphoinositide 3-kinase (PI3K)/AKT signaling pathway in PDGF-BB treated HSC-T6 cells. HSC-T6 cells were treated with $10 \mathrm{ng} / \mathrm{ml}$ PDGF-BB for $24 \mathrm{~h}$ and (A) the protein levels of p-AKT and AKT were detected using western blotting. (B) The relative p-AKT protein level was presented as a fold change. (C) The (p-AKT/ $\beta$-actin)/(AKT/ $\beta$-actin) ratio. Activated HSC-T6 cells were treated with 0, 20, 40, 80 and $160 \mu \mathrm{g} / \mathrm{ml}$ of PMS for $48 \mathrm{~h}$. (D) The protein levels of p-AKT and AKT were detected using western blotting. (E) The relative p-AKT protein level was presented as a fold change. (F) The (p-AKT/ $\beta$-actin)/(AKT/ $\beta$-actin) ratio. Data are presented as the mean \pm standard deviation. ${ }^{* *} \mathrm{P}<0.01$ vs. control group; ${ }^{\# P}<0.05$ and ${ }^{\# \#} \mathrm{P}<0.01 \mathrm{vs} .0 \mathrm{~h}$ treatment group. PMS, plantamajoside; p-, phosphorylated; PDGF-BB, platelet-derived growth factor BB; p, phosphorylated; AKT, protein kinase B.

no effective therapeutic interventions for liver fibrosis $(8,28)$. Therefore, it is of great significance to identify new and effective strategies for the treatment of liver fibrosis. There is increasing evidence indicates that several cell types are involved in the development of liver fibrosis $(29,30)$. However, activation of HSCs is a central process in the pathogenesis of liver fibrosis (4), and the activation of HSCs is mediated by a variety of inflammatory factors and growth factors (5). PMS, a major natural compound extracted from Psyllium asiatica, was demonstrated to regulate the inflammatory response and influence cell survival in vitro and in vivo (10-15). However, the potential effects of PMS on liver fibrosis had not been investigated. Therefore, the present study explored whether PMS exerts an antifibrotic effect by affecting the activation and survival of HSCs.
PDGF-BB is the most potent mitogenic cytokine for HSCs (29) and it inhibits HSC apoptosis, senescence or quiescence (31). PDGF-BB has been widely used for the activation of HSCs to study liver fibrosis in vitro $(19,20)$. In the present study, PDGF-BB was used to activate HSC-T6 cells. Consistent with previous studies $(19,20,32)$, PDGF-BB significantly activated HSC-T6 cells in the current study, demonstrated by increased cell proliferation, enhanced cell migration and invasion ability, and increased $\alpha$-SMA and Coll $\alpha 1$, markers of activated HSCs $(33,34)$. The activated HSC-T6 cells were treated with various concentrations $(0,20,80$ and $160 \mu \mathrm{g} / \mathrm{ml})$ of PMS, and cell proliferation, apoptosis, migration and invasion were determined by the CCK- 8 assay, flow cytometry and the Transwell assay, respectively. The results of the present study revealed that PMS might dose-dependently inhibit 
proliferation, induce cell apoptosis and decrease migration and invasion in PDGF-BB-treated HSC-T6 cells. Furthermore, PMS may dose-dependently reduce the protein and mRNA levels of $\alpha$-SMA and Coll $\alpha 1$ in HSC-T6 cells treated with PDGF-BB.

Multiple studies have revealed that the PI3K/AKT signaling pathway is activated during liver fibrosis and that it serves important roles in the activation of HSCs (35-38). Therefore, to explore the molecular mechanism of the antifibrotic effect of PMS, the PI3K/AKT signaling pathway was investigated in the present study. The PI3K/AKT signaling pathway activated by PDGF-BB treatment was inhibited by PMS treatment.

In summary, the results obtained in the current study suggested that PMS exerted an antifibrotic effect in the liver by inhibiting the activation of HSC and decreasing their survival via the PI3K/AKT signaling pathway. Therefore, PMS may be a promising therapeutic agent for the treatment of liver fibrosis. However, the present study had a number of limitations. The cell morphology prior to and following cell with PDGF-BB and PMS was not investigated. Only one HSC cell line was investigated in the current study. Furthermore, in vitro cell experiments differ from liver fibrosis in humans. The aim of the current study was to provide preliminary results of the effect of PMS on liver fibrosis. Further studies are required to substantiate the results obtained in the current study. Future studies may demonstrate the effects of PMS on the clonogenic capacity of HSCs and on other HSC cell lines as well as the effect of higher doses of PMS. Additionally, in vivo and clinical studies of the effect of PMS on liver fibrosis are required to demonstrate the effect of PMS on liver fibrosis. Furthermore, the mechanisms underlying the effect of PMS on PDGF-BB-treated HSC-T6 cells require further investigation.

\section{Acknowledgements}

Not applicable.

\section{Funding}

This study was supported by the Social Development Foundation of Nantong, Jiangsu, P.R. China (grant no. MS3201517).

\section{Availability of data and materials}

All datasets used and/or analyzed during the current study are available from the corresponding author on reasonable request.

\section{Authors' contributions}

YW contributed to study design, data collection and data analysis. DY contributed to data collection and data analysis. All authors contributed to interpreting the results and writing the manuscript.

\section{Ethics approval and consent to participate}

Not applicable.

\section{Patient consent for publication}

Not applicable.

\section{Competing interests}

The authors declare that they have no competing interests.

\section{References}

1. Lee UE and Friedman SL: Mechanisms of hepatic fibrogenesis. Best Pract Res Clinical Gastroenterol 25: 195-206, 2011.

2. Friedman SL: Mechanisms of hepatic fibrogenesis. Gastroenterology 134: 1655-1669, 2008.

3. Popov Y and Schuppan D: Targeting liver fbrosis: Strategies for development and validation of antifibrotic therapies. Hepatology 50: 1294-1306, 2009

4. Brown-Clay JD, Shenoy DN, Timofeeva O, Kallakury BV, Nandi AK and Banerjee PP: PBK/TOPK enhances aggressive phenotype in prostate cancer via $\beta$-catenin-TCF/LEF-mediated matrix metalloproteinases production and invasion. Oncotarget 6 : 15594-15609, 2015.

5. Zhang CY, Yuan WG, He P, Lei JH and Wang CX: Liver fibrosis and hepatic stellate cells: Etiology, pathological hallmarks and therapeutic targets. World J Gastroenterol 22: 10512-10522, 2016.

6. Bataller R and Brenner DA: Liver fibrosis. J Clin Invest 115: 209-218, 2005

7. Schuppan D: Liver fibrosis: Common mechanisms and antifibrotic therapies. Clin Res Hepatol Gastroenterol 39 (Suppl): S51-S59, 2015.

8. Koyama Y, Xu J, Liu X and Brenner DA: New developments on the treatment of liver fibrosis. Dig Dis 34: 589-596, 2016.

9. Samuelsen AB: The traditional uses, chemical constituents and biological activities of plantago major L. A review. J Ethnopharmacol 71: 1-21, 2000.

10. Huang DF, Tang YF, Nie SP, Wan Y, Xie MY and Xie XM: Effect of phenylethanoid glycosides and polysaccharides from the seed of Plantago asiatica L. on the maturation of murine bone marrow-derived dendritic cells. Eur J Pharmacol 620: 105-111, 2009.

11. Wu H, Zhao G, Jiang K, Chen X, Zhu Z, Qiu C, Li C and Deng G: Plantamajoside ameliorates lipopolysaccharide-induced acute lung injury via suppressing NF- $\mathrm{kB}$ and MAPK activation. Int Immunopharmacol 35: 315-322, 2016.

12. Pei S, Yang X, Wang H, Zhang H, Zhou B, Zhang D and Lin D: Plantamajoside, a potential anti-tumor herbal medicine inhibits breast cancer growth and pulmonary metastasis by decreasing the activity of matrix metalloproteinase-9 and -2 . BMC Cancer 15 : 965,2015

13. Li X, Chen D, Li M, Gao X, Shi G and Zhao H: Plantamajoside inhibits lipopolysaccharide-induced epithelial-mesenchymal transition through suppressing the NF- $\kappa \mathrm{B} / \mathrm{IL}-6$ signaling in esophageal squamous cell carcinoma cells. Biomed Pharmacother 102: 1045-1051, 2018.

14. Ma C and Ma W: Plantamajoside inhibits lipopolysaccharide-induced MUC5AC expression and inflammation through suppressing the PI3K/Akt and NF- $\mathrm{KB}$ signaling pathways in human airway epithelial cells. Inflammation 41: 795-802, 2018.

15. Son WR, Nam MH, Hong CO, Kim Y and Lee KW: Plantamajoside from Plantago asiatica modulates human umbilical vein endothelial cell dysfunction by glyceraldehyde-induced AGEs via MAPK/NF-кB. BMC Complement Altern Med 17: 66, 2017.

16. Puche JE, Saiman Y and Friedman SL: Hepatic stellate cells and liver fibrosis. Compr Physiol 3: 1473-1492, 2013.

17. Higashi T, Friedman SL and Hoshida Y: Hepatic stellate cells as key target in liver fibrosis. Adv Drug Deliv Rev 121: 27-42, 2017.

18. Panebianco C, Oben JA, Vinciguerra M and Pazienza V: Senescence in hepatic stellate cells as a mechanism of liver fibrosis reversal: A putative synergy between retinoic acid and PPAR-gamma signalings. Clin Exp Med 17: 269-280, 2017.

19. Lin X, Kong LN, Huang C, Ma TT, Meng XM, He Y, Wang QQ and Li J: Hesperetin derivative-7 inhibits PDGF-BB-induced hepatic stellate cell activation and proliferation by targeting Wnt/ $\beta$-catenin pathway. Int Immunopharmacol 25: 311-320, 2015

20. Wu X, Zhi F, Lun W, Deng Q and Zhang W: Baicalin inhibits PDGF-BB-induced hepatic stellate cell proliferation, apoptosis, invasion, migration and activation via the miR-3595/ACSL4 axis. Int J Mol Med 41: 1992-2002, 2018. 
21. Yang Y, Chen XX, Li WX, Wu XQ, Huang C, Xie J, Zhao YX, Meng XM and Li J: EZH2-mediated repression of Dkk1 promotes hepatic stellate cell activation and hepaticfibrosis. J Cell Mol Med 21: 2317-2328, 2017.

22. Yang L, Zhang CZ and Zhu QJ: Kangxian ruangan keli inhibits hepatic stellate cell proliferation mediated by PDGF. World J Gastroenterol 9: 2050-2053, 2003.

23. Livak KJ and Schmittgen TD: Analysis of relative gene expression data using real-time quantitative PCR and the 2(-Delta Delta C(T)) method. Methods 25:402-408, 2001.

24. Schuppan D: Structure of the extracellular matrix in normal and fibrotic liver: Collagens and glycoproteins. Semin Liver Dis 10: $1-10,1990$.

25. Anthony PP, Ishak KG, Nayak NC, Poulsen HE, Scheuer PJ and Sobin LH: The morphology of cirrhosis. Recommendations on defnition, nomenclature, and classifcation by a working group sponsored by the world health organization. J Clin Pathol 31 395-414, 1978.

26. Mormone E, George $\mathrm{J}$ and Nieto N: Molecular pathogenesis of hepatic fbrosis and current therapeutic approaches. Chem Biol Interact 193: 225-231, 2011.

27. Han YP, Zhou L, Wang J, Xiong S, Garner WL, French SW and Tsukamoto $\mathrm{H}$ : Essential role of matrix metalloproteinases in interleukin-1-induced myofibroblastic activation of hepatic stellate cell in collagen. J Biol Chem 279: 4820-4828, 2004.

28. Altamirano-Barrera A,Barranco-Fragoso B and Méndez-Sánchez N: Management strategies for liver fibrosis. Ann Hepatol 16: 48-56, 2017.

29. Gressner AM: Transdifferentiation of hepatic stellate cells (Ito cells) to myofibroblasts: A key event in hepatic fibrogenesis. Kidney Int 54 (Suppl): S39-S45, 1996.

30. Drescher HK, Schumacher F, Schenker T, Baues M, Lammers T, Hieronymus T, Trautwein C, Streetz KL and Kroy DC: c-Met signaling protects from nonalcoholic steatohepatitis-(NASH-) induced fibrosis in different liver cell types. Oxid Med Cell Longev 2018: 6957497, 2018.

31. Wong L, Yamasaki G, Johnson RJ and Friedman SL: Induction of beta-platelet-derived growth factor receptor in rat hepatic lipocytes during cellular activation in vivo and in culture. J Clin Invest 94: 1563-1569, 1994.
32. Wu CI, Hoffman JA, Shy BR, Ford EM, Fuchs E, Nguyen H and Merrill BJ: Function of Wnt/ $\beta$-catenin in counteracting Tcf3 repression through the Tcf 3 - $\beta$-catenin interaction. Development 139: 2118-2129, 2012.

33. Fang L, Zhan S, Huang C, Cheng X, Lv X, Si H and Li J: TRPM7 channel regulates PDGF-BB-induced proliferation of hepatic stellate cells via PI3K and ERK pathways. Toxicol Appl Pharmacol 272: 713-725, 2013.

34. Tao H, Huang C, Yang JJ, Ma TT, Bian EB, Zhang L, Lv XW, Jin Y and Li J: MeCP2 controls the expression of RASAL1 in the hepatic fibrosis in rats. Toxicology 290: 327-333, 2011.

35. Woodhoo A, Iruarrizaga-Lejarreta M,Beraza N, García-Rodríguez JL, Embade N, Fernández-Ramos D, Martínez-López N, Gutiérrez-De Juan V, Arteta B, Caballeria J, et al: Human antigen R contributes to hepatic stellate cell activation and liver fibrosis. Hepatology 56: 1870-1882, 2012.

36. El-Mihi KA, Kenawy HI, El-Karef A, Elsherbiny NM and Eissa LA: Naringin attenuates thioacetamide-induced liver fibrosis in rats through modulation of the PI3K/Akt pathway. Life Sci 187: 50-57, 2017.

37. Chen Q, Chen L, Wu X, Zhang F, Jin H, Lu C, Shao J, Kong D, Wu L and Zheng S: Dihydroartemisinin prevents liver fibrosis in bile duct ligated rats by inducing hepatic stellate cell apoptosis through modulating the PI3K/Akt pathway. IUBMB Life 68: 220-231, 2016.

38. Wang J, Chu ES, Chen HY, Man K, Go MY, Huang XR, Lan HY, Sung JJ and Yu J: microRNA-29b prevents liver fibrosis by attenuating hepatic stellate cell activation and inducing apoptosis through targeting PI3K/AKT pathway. Oncotarget 6: 7325-7338, 2015.

This work is licensed under a Creative Commons Attribution-NonCommercial-NoDerivatives 4.0 International (CC BY-NC-ND 4.0) License. 